\title{
Insulin sensitivity and insulin secretion in monozygotic and dizygotic twins
}

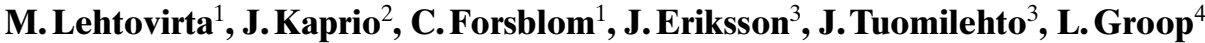 \\ ${ }^{1}$ Department of Medicine, University of Helsinki, Helsinki, Finland \\ ${ }^{2}$ Department of Public Health, University of Helsinki, Helsinki, Finland \\ ${ }^{3}$ National Public Health Institute, Helsinki, Finland \\ ${ }^{4}$ Department of Endocrinology, University of Lund, Malmö, Sweden
}

\section{Abstract}

Aims/hypothesis. To estimate the heritability of insulin sensitivity and insulin secretion, both of which are considered to contribute to the development of Type II (non-insulin-dependent) diabetes mellitus.

Methods. Intraclass correlation coefficients and heritability estimates for insulin sensitivity (euglycaemic clamp) as well as first-phase and late-phase insulin secretion (intravenous glucose tolerance test) were calculated in 21 monozygotic and 20 dizygotic twin pairs of the same sex between 54 and 72 years of age.

Results. Intrapair correlations for all traits were consistently higher in monozygotic than in dizygotic pairs. Insulin secretion correlated significantly only between monozygotic (first-phase $r=0.55 ; p=0.003$ and late-phase $r=0.66 ; p<0.001$ ) twins giving heritability estimates of 0.55 and 0.58 , respectively. Insulinstimulated glucose uptake showed a more modest correlation between monozygotic twins $(r=0.46$; $p=0.015)$. The heritability estimate was 0.37 . The heritability estimate for waist-to-hip ratio was 0.76 in female and 0.70 in male twins.

Conclusion/interpretation. Genetic variability seems to contribute to the variance of insulin sensitivity as well as of insulin secretion. In the current study, genetic variance accounted almost $60 \%$ for the variance in glucose-stimulated insulin secretion and almost $40 \%$ for the variance in insulin-stimulated glucose uptake. Our data is also compatible with findings in monogenic forms of diabetes in which genetic defects in insulin secretion play a predominant part in the pathogenesis of hyperglycaemia. [Diabetologia (2000) 43: 285-293]

Keywords Twins, monozygotic, dizygotic, heritability, insulin, insulin resistance.
Received: 21 September 1999 and in revised form: 25 November 1999

Corresponding author: M. Lehtovirta, Helsinki University Central Hospital, Department of Medicine, Division of Internal Medicine, PO Box 346, FIN-00029 HYKS, Finland Abbreviations: MZ, Monozygotic; DZ, dizygotic; MODY, maturity-onset diabetes of the young; WHR, waist-to-hip ratio; FFM, fat-free mass; SBP, systolic blood pressure; DBP, diastolic blood pressure; FPI, first-phase insulin secretion in IVGTT; LPI, late-phase insulin secretion in IVGTT; Intraclass $r$, intraclass correlation coefficient; $h^{2}$, heritability; A, additive component of variance; $\mathrm{C}$, variance component due to shared environment; $\mathrm{D}$, variance component due to dominance; $\mathrm{E}$, variance component due to non-shared environmental influences.
There is plenty of evidence that Type II (non-insulindependent) diabetes mellitusis a disease with a strong genetic predisposition [1-3]. In Finland, the estimated lifetime relative risk $(\lambda)$ of developing diabetes for a sibling to a person with Type II diabetes is about three [4]. This value decreases with age suggesting that environmental factors become more important with increasing age. Obesity and physical inactivity are the most important triggers of the disease. Several twin studies have provided unequivocal support for the genetic nature of the adult-onset type of diabetes, i.e. Type II diabetes, by showing a much higher concordance rate in monozygotic (MZ) compared with dizygotic (DZ) twins [1, 2, 5-9]. These findings have been challenged by some recent reports [10-13]. In a Finnish population-based twin study, 
the concordance for Type II diabetes was clearly lower than reported previously [10]. Nevertheless, the MZ twins still had a higher probandwise concordance rate for diabetes than the $\mathrm{DZ}$ twins. In a study from Denmark there was, however, no difference in the cumulative probandwise concordance rate for Type II diabetes between MZ and DZ twins [11]. Both in the Finnish and in the Danish study the results were dependent on the definition of diabetes. This is supported by the increase of the heritability estimate from $26 \%$ for Type II diabetes alone to $61 \%$ for abnormal glucose tolerance in a recent population-based twin study [12].

Both impaired insulin action and impaired insulin secretion are considered to contribute to the development of Type II diabetes $[14,15]$. There are, however, conflicting data on the relative contribution of these two defects to the manifestation of diabetes [16]. Insulin resistance is a consistent feature among first-degree relatives of patients with Type II diabetes and generally observed before any impairment in insulin secretion is seen $[15,17]$. These findings have been quoted as evidence that genetic defects causing insulin resistance are primary for the pathogenesis of Type II diabetes compared with defects in insulin secretion. In the interpretation of these findings, the possibility that defects in insulin secretion could be present, although not evident until glucose tolerance becomes impaired, should be considered [18].

Human genetics has been successful in finding the genes for the monogenic maturity onset diabetes of the young (MODY) forms of diabetes [19-21]. Mutations in the gene encoding enzyme glucokinase which regulates glucose metabolism in pancreatic beta cells and liver are responsible for the MODY2 subtype $[22,23]$. Mutations in three transcription factors, hepatocyte nuclear factor- $4 \alpha(H N F-4 \alpha)$ [21], hepatocyte nuclear factor- $1 \alpha(H N F-1 \alpha)$ [20] and insulin promoter factor-1 (IPF1) [24] have been shown to be responsible for the MODY1, MODY3 and MODY4 subtypes, respectively. It seems, however, to be a much harder task to unravel the genetic complexity of the most likely polygenic Type II diabetes. Given the heterogeneous nature of Type II diabetes it could be more rewarding to try to identify the responsible quantitative trait loci than to try to find linkage to diabetes itself. Before doing so, it is necessary to show that the traits (in the case of Type II diabetes: insulin sensitivity and insulin secretion) are genetically influenced. This can, for instance, be achieved by a twin study approach, i.e. by showing that MZ twins are more similar for the trait than DZ twins [25].

This study was designed to estimate the heritability of insulin sensitivity and insulin secretion. To achieve this goal, we measured insulin sensitivity (euglycaemic insulin clamp) and insulin secretion (insulin response to oral and intravenous glucose) in $\mathrm{MZ}$ and DZ twin pairs. The underlying assumption was that an inherited trait would show a stronger concordance in the MZ than in the DZ twins.

\section{Subjects and methods}

Subjects. The Finnish Twin Cohort Study is a programme for the study of genetic and environmental determinants of chronic disease and risk factors [26]. A baseline questionnaire was given in 1975, to twin pairs of same sex born before 1958, with an individual response rate of $89 \%$. Twin zygosity was determined in 1975 by examining the responses of both members of each twin pair to two questions on the similarity of appearance at primary school age. A set of decision rules was used to classify $93.1 \%$ of the twin pairs as monozygotic (MZ) or dizygotic (DZ), while $6.9 \%$ remained undetermined [27]. The questionnaire method has been shown to be highly accurate in a validation study using genetic markers [27]. For the present study, twin pairs resident in Helsinki and surrounding communities, with no diabetes according to earlier questionnaires, were randomly selected from the Twin Cohort and invited to participate in a study assessing glucose tolerance with OGTT. A random subset of these pairs was further invited to participate in more detailed studies of insulin sensitivity and insulin secretion. The final sample size was 41 pairs: $21 \mathrm{MZ}$ (6 women, 15 men) and $20 \mathrm{DZ}$ ( 7 women, 13 men). The study protocol was reviewed and approved by the local ethics committee. Informed consent was obtained from all subjects before their participation.

Information on self-reported birth weight and family history of diabetes was recorded, if available.

Assessment of body composition, lipids and blood pressure. After an overnight fast, a polyethylene catheter was placed in an antecubital vein and blood samples were drawn for the analysis of plasma glucose, serum insulin, total cholesterol, HDL-cholesterol and triglyceride concentrations. Height (to the nearest $\mathrm{cm}$ without shoes) and weight (to the nearest $\mathrm{kg}$ in light indoor clothing) were recorded. Body mass index (BMI) was calculated as weight $/$ height ${ }^{2}\left(\mathrm{~kg} / \mathrm{m}^{2}\right)$. Waist circumference (to the nearest $\mathrm{cm}$ without clothes) was measured with a non-elastic soft tape midway between the lowest rib and the iliac crest on standing subjects. Hip circumference (to the nearest $\mathrm{cm}$ without clothes) was measured over the widest part of the gluteal region. As a measure of abdominal obesity, waist-to-hip ratio (WHR) was calculated. Fat-free mass (FFM) and fat mass (percentage) were measured using a bioelectrical impedance method [28, 29]. Systolic (SBP) and diastolic (DBP) blood pressure were measured with a mercury sphygmomanometer (Speidel and Keller, Jungingen, Germany) from the right arm of the subjects in sitting position after a 15 -min rest. The results are expressed as the mean of three consecutive readings.

Measurement of insulin secretion and insulin sensitivity. Insulin secretion was measured by an IVGTT during which $0.3 \mathrm{~g} / \mathrm{kg}$ body weight of glucose (maximum dose $35 \mathrm{~g}$ ) was infused intravenously for $2 \mathrm{~min}$ and blood samples for the analysis of plasma glucose and serum insulin were drawn at $0,2,4,6,8$, $10,20,30,40,50$ and $60 \mathrm{~min}$. The first-phase insulin secretion (FPI) was calculated as the incremental area under the insulin curve during the first $10 \mathrm{~min}$ and the late-phase insulin secretion (LPI) as the incremental area under insulin curve during the last $50 \mathrm{~min}$ of the IVGTT. Whole-body glucose uptake was quantified with a $160 \mathrm{~min}$ euglycaemic hyperinsulinaemic $\left(45 \mathrm{mU} / \mathrm{m}^{2}\right)$ clamp as previously described [15]. The IVGTT and the clamp were done on different days in $14 \mathrm{MZ}$ and 5 
Table 1. Clinical and metabolic characteristics of monozygotic (MZ) and dizygotic (DZ) twins

\begin{tabular}{|c|c|c|c|}
\hline & MZ & DZ & $p$ \\
\hline Number of pairs (female/male) & $21(6 / 15)$ & $20(7 / 13)$ & \\
\hline Age (year) & $61.4 \pm 4.3$ & $63.5 \pm 2.3$ & 0.009 \\
\hline $\mathrm{BMI}\left(\mathrm{kg} / \mathrm{m}^{2}\right)$ & $26.2 \pm 3.1$ & $26.5 \pm 3.0$ & NS \\
\hline Fat mass $(\%)$ & $23.0 \pm 6.4$ & $24.6 \pm 6.2$ & NS \\
\hline Systolic blood pressure (mm HG) & $133 \pm 17$ & $134 \pm 15$ & NS \\
\hline Diastolic blood pressure (mm HG) & $83 \pm 9$ & $82 \pm 8$ & NS \\
\hline Triglycerides (mmol/l) & $1.17 \pm 0.51$ & $1.34 \pm 0.69$ & NS \\
\hline Basal NEFA $(\mu \mathrm{mol} / \mathrm{l})$ & $676 \pm 193$ & $708 \pm 214$ & NS \\
\hline Clamp NEFA $(\mu \mathrm{mol} / 1)$ & $72 \pm 40$ & $57 \pm 27$ & 0.052 \\
\hline Fasting plasma glucose $(\mathrm{mmol} / \mathrm{l})$ & $5.5 \pm 0.5$ & $5.8 \pm 0.6$ & 0.04 \\
\hline Fasting serum insulin $(\mathrm{pmol} / \mathrm{l})$ & $47 \pm 26$ & $44 \pm 22$ & NS \\
\hline First-phase insulin secretion $\left(\mathrm{pmol} \cdot \mathrm{l}^{-1} \cdot 10 \mathrm{~min}^{-1}\right)$ & $1817 \pm 1234$ & $1383 \pm 974$ & NS \\
\hline
\end{tabular}

Data presented as means \pm SD

DZ twin pairs and on the same day in $8 \mathrm{MZ}$ and $15 \mathrm{DZ}$ pairs (Botnia clamp [30]). When done on the same day, the clamp was started 30 min after the end of the IVGTT. In these subjects, glucose uptake value was adjusted for the influence of the preceding IVGTT. In the whole material, a preceding IVGTT resulted in a $7 \%$ increase in the glucose uptake during the clamp. Both members of a twin pair participated in the same protocol. In addition, a separate analysis was done stratifying twin pairs for clamps done on the same day or different days.

Assays. Plasma glucose was measured on duplicates with a glucose oxidase method using a Beckman Glucose Analyzer II (Beckman Instruments, Fullerton, Calif., USA). Serum insulin concentrations were measured by radioimmunoassay (Pharmacia, Uppsala, Sweden) with an interassay CV of $5 \%$. Serum total and HDL-cholesterol (after precipitation) and triglyceride concentrations were measured by specific enzymatic methods (Boehringer Mannheim, Mannheim, Germany). Serum non-esterified fatty acid (NEFA) concentrations were analysed with an enzymatic method (Wako Chemicals, Neuss, Germany) from serum samples drawn in the fasting state and at the end of the clamp.

Statistical analysis. Data are expressed as means \pm SD. Insulin values were log transformed because of their skewed distribution. Intraclass correlation coefficients (intraclass $r$ ) and heritability estimates $\left(h^{2}\right)[31,32]$ were calculated using residuals of trait values. The data were also analysed separately for female and male twins whenever sex related effects were detected. Differences between the MZ and DZ twin pairs were tested with two-tailed $t$ test. Pearson's correlation coefficients were calculated for the phenotypic correlations using the SOLO statistical package (Biomedical Data Processing. Los Angeles, Calif., USA).

Intraclass correlations and model-fitting analyses. To estimate genetic and environmental components of variance of the traits, standard univariate twin analyses were carried out [31]. These included the test for homogeneity of the mean values and variances across the twin type. Maximum likelihood analyses based on sample covariance matrices were used to estimate the components of variance $[31,32]$. In the current study of twins reared together it is possible to model four separate com- ponents: (A) an additive genetic component, (D) effects due to dominance, (C) shared and (E) non-shared environmental components. One can fit the models based on different combinations of these variables: AE, ACE, ADE and CE but the effects due to dominance and shared environmental effects cannot be simultaneously modelled with data from twins reared together [32]. Chi-squared goodness-of-fit statistics were used to assess how well the model fitted the data. The relative goodness of fit of different models was tested by using the likelihood ratio test, which is based on the more general model (in this case, AE) being nested in a detailed model (for example, $\mathrm{ADE}$ ). Comparing the $\mathrm{AE}$ and $\mathrm{ADE}$ model gives the following likelihood ratio: chi-squared (AE) - chi-squared (ADE), with degrees of freedom $=(d f(\mathrm{AE})-d f(\mathrm{ADE}))$. If the new chi-squared thus obtained, i.e. the likelihood ratio is significant at $p=0.05$ level it means that there is deterioration in the fit of the model when the extra variable, $\mathrm{D}$ in the example, is fixed at zero. A practical and alternate way to evaluate and express variance components is to use intraclass-correlation coefficients for $\mathrm{MZ}$ and $\mathrm{DZ}$ pairs. This is somewhat less accurate than the model-fitting procedure, because the correlation coefficient is a function of both covariances and variances [32], but lends itself to easier interpretation. It can be shown, that in the presence of purely additive genetic variance (in addition to non-genetic influences from the unique environment), intraclass $r(\mathrm{MZ})=2 \mathrm{x}$ intraclass $r(\mathrm{DZ})$. Environmental factors shared by the twins tend to decrease intraclass $r$ (MZ):intraclass $r$ (DZ) ratio, whereas non-additive genetic factors increase it [32].

\section{Results}

Clinical characteristics of $M Z$ and DZ twins (Table 1). The MZ twins were younger than the DZ twins $(p=0.009)$. No age-related associations were, however, observed. One MZ (2.4\%) and three DZ (7.5\%) twins fulfilled the 1985 WHO criteria for diabetes [33]. Based on the same criteria, nine MZ (21.4\%) and nine DZ (22.5\%) twins had impaired glucose tolerance (IGT). One diabetic MZ twin had a co-twin with IGT and one DZ twin pair was concordant for 
Table 2. Intraclass correlation coefficients $(r)$ and the AE-model based heritability estimates $\left(h^{2}\right)$ in monozygotic (MZ) and dizygotic (DZ) twins

\begin{tabular}{|c|c|c|c|c|c|c|}
\hline & \multicolumn{2}{|l|}{ MZ } & \multicolumn{2}{|l|}{$\mathrm{DZ}$} & \multirow[b]{2}{*}{$\mathrm{h}^{2}$} & \multirow[b]{2}{*}{ SE } \\
\hline & $r$ & $\mathrm{p}$ & $\mathrm{r}$ & $\mathrm{p}$ & & \\
\hline BMI & 0.60 & 0.001 & 0.04 & 0.43 & 0.54 & 0.20 \\
\hline Waist-to-hip ratio - female twins & 0.89 & 0.002 & 0.13 & 0.38 & 0.76 & 0.32 \\
\hline Waist-to-hip ratio-male twins & 0.68 & 0.003 & 0.08 & 0.39 & 0.70 & 0.29 \\
\hline Fat mass & 0.77 & $<0.001$ & 0.32 & 0.075 & 0.74 & 0.17 \\
\hline Fat mass - female twins & 0.81 & 0.008 & 0.21 & 0.30 & 0.77 & 0.39 \\
\hline Fasting glucose - female twins & 0.01 & 0.48 & 0.63 & 0.037 & - & - \\
\hline Fasting glucose - male twins & 0.36 & 0.08 & 0.16 & 0.28 & - & - \\
\hline Fasting insulin & 0.49 & 0.009 & -0.06 & 0.61 & 0.41 & 0.20 \\
\hline
\end{tabular}

$\mathrm{SE}=$ standard error for $h^{2}$. No $h^{2}$ could be calculated for sex-specific fasting glucose.

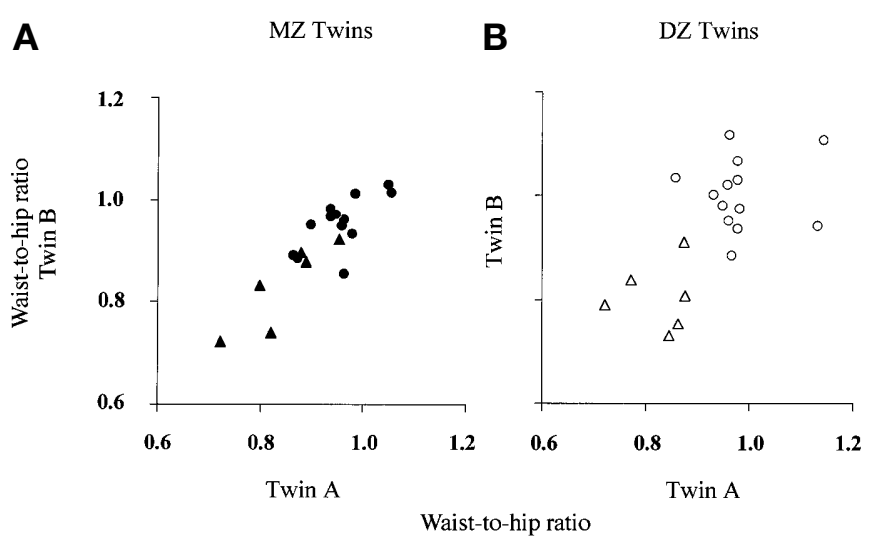

Fig. 1 A, B. Pairwise scatterplots of WHR in $\mathrm{MZ}(\mathbf{A}, r=0.88$, $p<0.001)$ and DZ $(\mathbf{B}, r=0.64, p=0.001)$ twin pairs. Triangles represent female and circles male twin pairs. Twin A value on the $\mathrm{x}$-axis is plotted against twin $\mathrm{B}$ value on the $\mathrm{y}$-axis

IGT. All other twins with IGT or diabetes had a normoglycaemic co-twin. There were $12 \mathrm{MZ}(57 \%)$ and 9 DZ (45\%) pairs who had a first-degree family history of diabetes. The $\mathrm{MZ}$ and $\mathrm{DZ}$ twins differed slightly in their fasting plasma glucose values $(p=0.04)$. The difference in glucose disappeared after exclusion of the diabetic pairs $(5.5 \pm 0.5$ vs $5.7 \pm 0.5 \mathrm{mmol} / \mathrm{l}, p=0.18)$. The MZ twins had somewhat higher insulin values than the DZ twins during the late (LPI, $p=0.018$ ) phase of the IVGTT. Insulin-stimulated glucose uptake did not differ between $\mathrm{MZ}$ and DZ twins. The self-reported birth weights in $14 \mathrm{MZ}$ and $12 \mathrm{DZ}$ twin pairs were $2683 \pm 597 \mathrm{~g}$ and $2645 \pm 480 \mathrm{~g}$, respectively.

Intraclass correlations and heritability estimates of the anthropometric measures. Intraclass correlations provide estimates of the similarity between members of a twin pair. In general, MZ intraclass $r$ values were higher than the corresponding DZ values, indicating the importance of genetic influences for the variables. The degree to which genes influenced the variables observed was estimated by calculating $h^{2}$ using the maximum likelihood analysis. The AE model (additive genetic and non-shared environmental factors) fitted the data best for most traits (Table 2). The intraclass $r$ for BMI $(r=0.60, p=0.001)$ was high in MZ but not in DZ twins ( $r=0.04$, NS). The corresponding $h^{2}$ was 0.54 . Waist-to-hip intraclass $r$ values were high both in $\mathrm{MZ}(r=0.88, p<0.001)$ and $\mathrm{DZ}$ $(r=0.64, p=0.001)$ twins yielding a high $h^{2}$ of 0.89 (Fig. 1). A subanalysis resulted in higher values for female (intraclass $r=0.89, p=0.002$ ) than for male (intraclass $r=0.68, p=0.003) \mathrm{MZ}$ twins and non-significant intraclass $r$ in DZ twins ( $p=0.38$ for female and $p=0.39$ for male twins). The heritability estimates for WHR were 0.76 for female and 0.70 for male twins, respectively. The sex-association was more pronounced in fat mass with female MZ twins (intraclass $r=0.81, p=0.008$ ) having clearly higher intraclass $r$ than the male MZ twins (intraclass $r=0.42$, $p=0.047)$. The fat mass intraclass $r$ values were nonsignificant in DZ twins $(p=0.30$ for female and $p=0.95$ for male twins). The estimates for fat mass $h^{2}$ were 0.77 for female and 0.17 for male twins.

Intraclass correlations and heritability estimates of insulin secretion and insulin-mediated glucose uptake. Fasting insulin (MZ intraclass $r=0.49, p=0.009$; Table 2), FPI (intraclass $r=0.55, p=0.003$; Tables 3 and 4, Fig. 2) and LPI (intraclass $r=0.66, p<0.001$; Tables 3 and 4) were significantly correlated between MZ but not between DZ twins. The corresponding heritability estimates were 0.41 for fasting insulin, 0.55 for FPI and 0.58 for LPI, respectively. Insulinstimulated glucose uptake correlated between MZ (intraclass $r=0.46, p=0.015$ ) but not between DZ (intraclass $r=0.01$, NS) twins (Fig. 3) and the heritability estimate was 0.37 . After the exclusion of diabetic pairs, the intraclass $r$ and $h^{2}$ of glucose uptake, FPI and LPI, respectively, remained unchanged.

Insulin secretion is dependent upon the degree of insulin sensitivity. In the current study, both FPI 
Table 3. Covariance matrices of first (FPI) and late (LPI) phase insulin secretion and insulin-stimulated glucose uptake between twins in monozygotic (MZ) and dizygotic (DZ) twin pairs

\begin{tabular}{|c|c|c|c|c|c|c|c|}
\hline & & FPI & & LPI & & Glucos & \\
\hline & & Twin 1 & Twin 2 & Twin 1 & Twin 2 & Twin 1 & Twin 2 \\
\hline $\mathrm{MZ}$ & Twin 1 & 0.4875 & 0.55 & 0.0725 & 0.66 & 7.2008 & 0.46 \\
\hline DZ & Twin 1 & 0.4008 & 0.24 & 0.0549 & 0.11 & 6.5956 & 0.01 \\
\hline & Twin 2 & 0.1318 & 0.6962 & 0.0051 & 0.0412 & 0.0590 & 3.3953 \\
\hline
\end{tabular}

Along diagonal are variances, below diagonal covariance and above diagonal (in bold) intraclass correlation. Insulin secretion values have been log-transformed

Table 4. Variance components for first (FPI) and late (LPI) phase insulin secretion and glucose uptake from monozygotic (MZ) and dizygotic (DZ) twin pairs

\begin{tabular}{lllll}
\hline $\begin{array}{l}\text { Source of } \\
\text { variation }\end{array}$ & & FPI & LPI & $\begin{array}{l}\text { Glucose } \\
\text { uptake }\end{array}$ \\
\hline $\begin{array}{l}\text { Additive genetic } \\
\text { variance }\end{array}$ & $\mathrm{V}_{\mathrm{A}}$ & 0.305 & 0.034 & 2.172 \\
Unique and & $\mathrm{V}_{\mathrm{E}}$ & $(0.102)$ & $(0.010)$ & $(1.372)$ \\
error variance & & 0.249 & 0.025 & 3.695 \\
Heritability & $\mathrm{V}_{\mathrm{A}} /\left(\mathrm{V}_{\mathrm{A}}+\mathrm{V}_{\mathrm{E}}\right)$ & 0.550 & 0.580 & 0.370 \\
& & $(0.184)$ & $(0.174)$ & $(0.234)$ \\
Goodness of fit & $\chi^{2}$ & 1.93 & 1.99 & 3.45 \\
& $d f$ & 4 & 4 & 4 \\
& $p$ value & 0.749 & 0.737 & 0.486 \\
\hline
\end{tabular}

Maximum likelihood estimates (and standard errors) of additive genetic and unshared components of variance. For calculation of variance components of FPI and LPI, log-transformed insulin values have been used

$(r=-0.26, p=0.02)$ and LPI $(r=-0.46, p<0.001)$ correlated with insulin-stimulated glucose uptake. To control for this influence, we estimated the intraclass $r$ and $h^{2}$ for FPI and LPI, respectively, adjusted for glucose uptake. Adjusting FPI for insulin sensitivity decreased the MZ intraclass $r$ from 0.55 to 0.41 $(p=0.027)$ and $h^{2}$ from 0.55 to 0.41 . The corresponding MZ intraclass $r$ for LPI decreased from 0.66 to $0.44(p=0.019)$ and $h^{2}$ from 0.58 to 0.41 .

The intraclass $r$ for glucose uptake was somewhat higher among the $14 \mathrm{MZ}$ twin pairs (intraclass $r=0.51$ ) who participated in IVGTT and clamp on different days compared with the $8 \mathrm{MZ}$ twin pairs (intraclass $r=0.44$ ) who underwent both studies on the same day. The DZ twins had the same patterns of intraclass $r$ when studied both on different days (intraclass $r=0.22 ; 7$ pairs) and on the same day (intraclass $r=-0.01 ; 12$ pairs).

\section{Discussion}

The present study provides evidence that both insulin secretion and insulin sensitivity are under genetic control. In our study, environmental factors seemed to play a major part in determining insulin sensitivity.
It is known from other twin studies that MZ twins maintain their unique intrapair resemblance for many traits despite ageing [34-36]. The influence of the environment shared by a twin pair usually decreases after 20 years of age but the relative contribution of the identical genetic architecture shared by $\mathrm{MZ}$ twins increases [37]. Although the AE-model fit the data best for most traits in the present study, the DZ correlation was often less than half of the MZ correlation, suggesting a contribution from effects due to dominance. The MZ twins not only share all their alleles; they share all their allelic combinations as well. Dizygotic twins share on average half of their alleles, but only one quarter of the effects of dominance, which are due to allelic combinations. The comparison of MZ and DZ twin similarity has a relatively poor power to differentiate between additive and non-additive effects [32]. With ageing, DZ twins differ increasingly with regard to their behavioural, anatomical and physiological characteristics. Because the number of twin pairs in our study was modest, the heritability estimates could differ somewhat from true values in the population. On the other hand, the high concordance for most variables in our 60-year old $\mathrm{MZ}$ twins provide strong evidence for a genetic background.

We did not include twins with known diabetes in the study but three DZ and one MZ twin turned out to have undiagnosed diabetes based upon OGTT with rather moderate increases in blood glucose. To avoid potential biases, we analysed the data both with and without including these subjects. The two analyses gave almost identical heritability estimates for insulin secretion and insulin sensitivity.

Our findings of a strong heritability of insulin secretion might seem inconsistent with published data that favour a familial clustering of insulin resistance $[17,37-39]$, rather than of insulin secretion. We [40, $41]$ and others $[42,43]$ have shown impaired insulinstimulated glucose uptake in first-degree relatives of patients with Type II diabetes. In our own study, insulin secretion measured during a hyperglycaemic clamp was normal when glucose tolerance was normal [15]. It was not until the stage of IGT that we could show an impairment in the first-phase insulin 


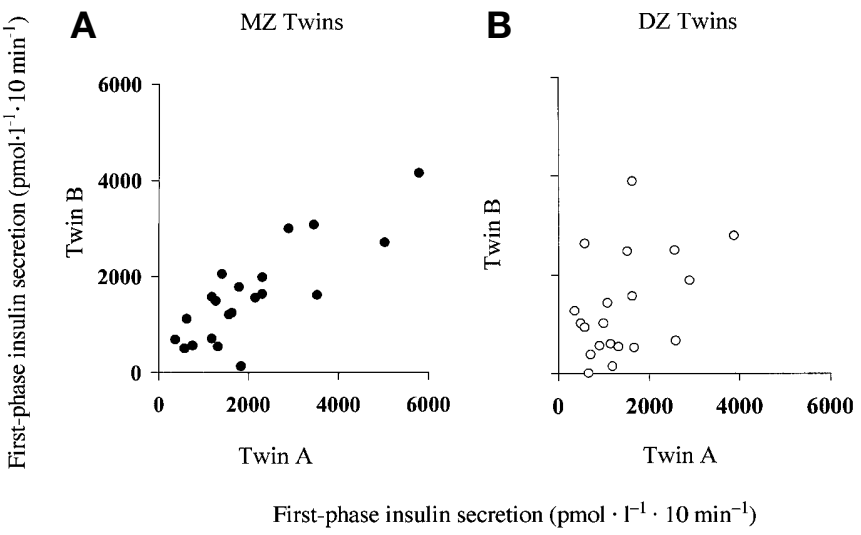

Fig. 2A, B. Pairwise scatterplots of first-phase insulin secretion among twins in $\mathrm{MZ}(\mathbf{A}, r=0.55, p<0.003)$ and $\mathrm{DZ}$ $(\mathbf{B}, r=0.24$, NS) twin pairs. Twin A value on the $\mathrm{X}$-axis is plotted against twin $\mathrm{B}$ value on the $\mathrm{y}$-axis

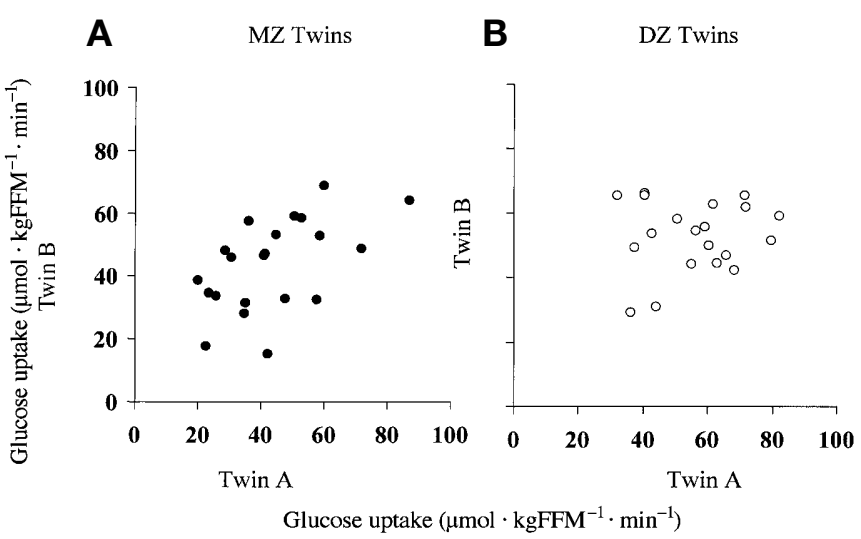

Fig. 3 A, B. Pairwise scatterplots of glucose uptake among MZ $(\mathbf{A}, r=0.46, p=0.015)$ and DZ (B, $r=0.01$, NS) twin pairs. Glucose uptake is expressed per $\mathrm{kg}$ fat-free mass (FFM). Twin A value on the $\mathrm{x}$-axis is plotted against twin $\mathrm{B}$ value on the $\mathrm{y}$-axis

secretion [15]. Similarly, in another study, using a number of sophisticated methods to measure insulin secretion, impaired insulin secretion could not be shown until the patients had impaired glucose tolerance [44]. This does not mean that insulin resistance is an inherited early prediabetic defect and impaired insulin secretion is not. It could merely reflect the sensitivity of the methods used for measuring these traits [16]. Current methods for measuring insulin secretion are not sensitive enough when subjects have normal glucose tolerance.

There is little available information on the heritability of insulin secretion in non-diabetic people. A study of MZ twins discordant for Type II diabetes showed impaired insulin secretion in addition to impaired insulin resistance in the non-diabetic twin [45]. The group of non-diabetic twins included, however, subjects with IGT [45]. In an early study of young healthy $\mathrm{MZ}$ and $\mathrm{DZ}$ twins, intraclass correla- tions were obtained for glucose-stimulated insulin secretion measured during a glucose infusion [46]. The intraclass correlation for insulin secretion in the MZ twins was in the same range as in our study whereas the value in the DZ twins was somewhat higher than in our DZ twins. No information was, however, given on the accompanying insulin sensitivity in the twins [46].

Our experimental protocol combining an IVGTT with a euglycaemic clamp allowed us to estimate insulin secretion in relation to insulin sensitivity. The first or early phase of insulin secretion consists of exocytosis of insulin-containing vesicles located already at the beta-cell plasma membrane [47]. Less than 100 insulin-containing granules per beta cell constitute this readily releasable pool which is released immediately in response to glucose. After a short delay of approximately $10 \mathrm{~s}$, granules further away are recruited to this pool and insulin secretion increases in a time-dependent and ATP-dependent manner. In contrast, the very first part of the earlyphase insulin secretion is independent of ATP. The whole process from the activation of the insulin gene transcription to the exocytosis of insulin takes approximately $2 \mathrm{~h}$ [47]. It is naturally difficult to extrapolate patchclamp data in a single beta cell to our experimental setting. It is, however, likely that FPI is influenced both by an ATP-independent immediately releasable and by an ATP-dependent pool, whereas LPI only consists of ATP-dependent insulin secretion. Late-phase insulin secretion showed a stronger correlation with glucose uptake $(r=-0.46 ; p<0.001)$ than FPI $(r=-0.26 ; p<0.02)$. This is not surprising because the ambient glucose concentration which provides the stimulus for the insulin secretion is dependent upon clearance of glucose and thereby of the degree of insulin sensitivity. Adjustment of FPI for insulin sensitivity had thus relatively little influence on the intrapair $r$ and $h^{2}$. First-phase insulin secretion, as measured during an IVGTT, can, therefore be considered as a useful quantitative trait for insulin secretion in genetic studies.

The MZ intraclass correlation for insulin-stimulated glucose uptake seemed to be lower than for insulin secretion and both were greater than the corresponding DZ twin correlation. Formal testing for the presence of genetic variance was, however, done using structural equation modelling which takes full advantage of all the information on twin variances and covariances. In some of the twin pairs, we applied the combination of IVGTT and euglycaemic clamp on the same day. The glucose uptake measured using this method correlates strongly with the glucose uptake measured without preceding IVGTT $(r=0.98$, $n=10$ ) [30]. In the current study, a separate analysis gave almost similar intraclass $r$ for the twins studied on different days. The slightly higher intraclass $r$ in MZ twins who underwent IVGTT and clamp on dif- 
ferent days indicates that it is possible that the genetic variance component of glucose uptake can be larger in the general population than what we estimated in our study.

There are no studies in normal twins using the clamp method to estimate insulin sensitivity. Practically all heritability estimates of insulin sensitivity or insulin resistance have relied on fasting insulin and glucose values [48-52]. The heritability estimate for fasting insulin, regarded as the best single indirect measure of insulin sensitivity in population studies [53], was 0.41 in our study. It has been estimated to range from 0.20 to 0.54 in other studies $[48,50-52]$. In one study a heritability estimate of 0.66 for insulin resistance calculated as fasting insu$\operatorname{lin} /\left(22.5 \times \mathrm{e}^{-\ln \text { glucose }}\right)$ was obtained [50]. Another study of twin pairs reared together or apart, estimated that $39 \%$ of the variance of insulin resistance, calculated as fasting insulin $\times$ fasting glucose $/ 22.5$, was attributable to genetic influences [49]. We obtained a $h^{2}$ of 0.37 by using a method regarded as the "golden standard" for measuring insulin sensitivity. The correlation between insulin-mediated glucose uptake and fasting insulin was 0.50 in our study and 0.48 if insulin was replaced with the insulin resistance estimate used in Hong's study (data not shown). Fasting insulin, therefore, explained only $25 \%$ of the variance of glucose uptake measured by using the clamp.

Physical fitness and insulin sensitivity are known to be associated $[54,55]$ and the effect of inheritance on physical activity has been estimated to be low [56, 57]. It can reasonably be assumed that the exercise habits of the twins also contributed in our study to the variance observed in glucose uptake. In addition to exercise, dietary factors are known to influence insulin sensitivity [58]. In a study of adult $\mathrm{MZ}$ and $\mathrm{DZ}$ twins, $65 \%$ of the variance in energy intake was attributable to genetic factors [59]. In other twin studies the caloric intake has been shown to influence insulin sensitivity mainly through obesity $[58,60]$. Cigarette smokers have been shown to be insulin resistant and hyperinsulinaemic [61]. We were, however, not able to detect any correlation between smoking and glucose uptake (data not shown) observed in other studies. The current study setting has a limited ability to decompose in detail the environmental variance component of glucose uptake. Our data indicates, however, that the contribution of genetic factors to insulin sensitivity could be smaller than previously estimated.

We were not able to replicate the same recent findings which gave rise to the hypothesis that the intrauterine competition of nutrition between $\mathrm{MZ}$ twins results in glucose intolerance and insulin resistance during their adult life [62]. Our MZ twins, admittedly, had higher LPI than the DZ twins, but in order to test their hypothesis detailed information on chorio- nicity and pregnancy, that was not available to us, should be used.

Our observation of the genetic factors explaining more than $70 \%$ of the variance in WHR, when the effect of sex had been taken into account, is consistent with heritability estimates obtained from other family studies [63-65]. We have shown previously that an increased WHR is an early feature of first-degree relatives of patients with Type II diabetes and associated with features of the metabolic or insulin-resistance syndrome [66]. Common variation in genes regulating lipolysis in visceral fat could predispose to abdominal obesity and the metabolic syndrome. Despite both positive and negative results in association studies $[67,68]$, current evidence supports the view that a mutation in the $\beta 3$-adrenergic receptor gene is important for the metabolic alterations in abdominal obesity and insulin resistance $[69,70]$. This is further supported by the finding that when expressed, the mutation is associated with impaired catecholaminestimulated lipolysis [71, 72]. In addition, a variant in the gene for hormone sensitive lipase was more often transmitted from heterozygous diabetic parents to the abdominal obese offspring [73]. This variant was particularly common in Type II diabetic patients with a high WHR.

Genes seem to contribute to the variance of insulin sensitivity as well as of insulin secretion. In the current study, this variance component accounted almost $60 \%$ for the variance in glucose-stimulated insulin secretion and almost $40 \%$ for the variance in insulinstimulated glucose uptake. Our data is also compatible with findings in monogenic forms of diabetes in which genetic defects in insulin secretion play a predominant part in the pathogenesis of hyperglycaemia.

Acknowledgements. This study was supported by the following grants: Finska Läkaresällskapet, The Finnish Diabetes Research Society (both to M. Lehtovirta, C. Forsblom), The Research Foundation of the Orion Corporation, The FinnishNorwegian Medical Foundation, The Novo Nordisk Foundation (all to M. Lehtovirta), Yrjö Jahnsson Foundation (J. Tuomilehto), Sigrid Juselius Foundation, an EEC grant BMH4CT9S-0662 (both to L. Groop) and by the grants \#38332 and \#42044 from the Academy of Finland (J. Kaprio, J. Tuomilehto). We thank Mrs. S. Heikkinen, Ms A. Tapio, Mrs. M. Ben-Ami, Mrs. H. Åkerfelt, Ms T. Ilomäki, Ms L. Toivanen and Mr. E. Laurila for skillful assistance. The invaluable support and advice provided by $\mathrm{C}$. Saloranta, $\mathrm{MD}, \mathrm{PhD}$, is gratefully acknowledged.

\section{References}

1. Barnett A, Eff C, Leslie R, Pyke D (1981) Diabetes in identical twins. A study of 200 pairs. Diabetologia 20: 87-93

2. Newman B, Selby J, King M, Slemenda C, Fabsitz R, Friedman G (1987) Concordance for Type II (non-insulin-dependent) diabetes mellitus in male twins. Diabetologia 30: 763-768 
3. Köbberling J, Tillil H (1982) Empirical risk figures for first degree relatives of non-insulin dependent diabetics. In: Köbberling J, Tattersall R (eds) Serono Symposium No 47. The Genetics of Diabetes Mellitus. Academic Press, London, New York, pp 201-209

4. Ghosh S, Hauser ER, Magnuson VL et al. (1998) A large sample of Finnish diabetic sib-pairs reveals no evidence for a non-insulin-dependent diabetes mellitus susceptibility locus at 2qter. J Clin Invest 102: 704-709

5. Then Berg H (1938) Die Erbbiologie des diabetes mellitus. Archive für Rassen- und Gesellschaftsbiologie einschliesslich Rassen- und Gesellschaftshygiene 32: 289

6. Harvald B, Hauge M (1963) Selection in diabetes in modern society. Acta Med Scand 173: 459-465

7. Gottlieb MS, Root HF (1968) Diabetes mellitus in twins. Diabetes 17: 693-704

8. Anonymous (1988) Diabetes mellitus in twins: a cooperative study in Japan. Committee on Diabetic Twins, Japan Diabetes Society. Diabetes Res Clin Pract 5: 271-280

9. Medici F, Hawa M, Ianari A, Pyke DA, Leslie RD (1999) Concordance rate for type II diabetes mellitus in monozygotic twins: actuarial analysis. Diabetologia 42: 146-150

10. Kaprio J, Tuomilehto J, Koskenvuo M et al. (1992) Concordance for Type I (insulin-dependent) and Type II (non-insulin-dependent) diabetes mellitus in a population-based cohort of twins in Finland. Diabetologia 35: 1060-1067

11. Poulsen P, Vaag AA, Kyvik KO, Jensen DM, Beck-Nielsen $\mathrm{H}$ (1997) Low birth weight is associated with NIDDM in discordant monozygotic and dizygotic twin pairs. Diabetologia 40: 439-446

12. Poulsen P, Kyvik KO, Vaag A, Beck-Nielsen H (1999) Heritability of Type II (non-insulin-dependent) diabetes mellitus and abnormal glucose tolerance - a population-based twin study. Diabetologia 42: 139-145

13. Hawkes CH (1997) Twin studies in diabetes mellitus. Diabet Med 14: 347-352

14. DeFronzo R, Ferrannini E (1991) Insulin resistance: a multifaceted syndrome responsible for NIDDM, obesity, hypertension, dyslipidemia, and atherosclerotic cardiovascular disease. Diabetes Care 14: 173-194

15. Eriksson J, Franssila-Kallunki A, Ekstrand A et al. (1989) Early metabolic defects in persons at increased risk for non-insulin-dependent diabetes mellitus. N Engl J Med 321: 337-343

16. Groop LC, Widen E, Ferrannini E (1993) Insulin resistance and insulin deficiency in the pathogenesis of Type II (noninsulin-dependent) diabetes mellitus: errors of metabolism or of methods? Diabetologia 36: 1326-1331

17. Lillioja S, Mott DM, Zawadzki JK et al. (1987) In vivo insulin action is familial characteristic in nondiabetic Pima Indians. Diabetes 36: 1329-1335

18. Byrne MM, Sturis J, Fajans SS et al. (1995) Altered insulin secretory responses to glucose in subjects with a mutation in the MODY1 gene on chromosome 20. Diabetes 44: 699-704

19. Chevre JC, Hani EH, Boutin P et al. (1998) Mutation screening in 18 Caucasian families suggest the existence of other MODY genes. Diabetologia 41: 1017-1023

20. Yamagata K, Oda N, Kaisaki P et al. (1996) Mutations in the hepatocyte nuclear factor-1alpha gene in maturity-onset diabetes of the young (MODY3). Nature 384: 455-458

21. Yamagata K, Furuta H, Oda N et al. (1996) Mutations in the hepatocyte nuclear factor-4alpha gene in maturity-onset diabetes of the young (MODY1). Nature 384: 458-460

22. Froguel P, Vaxillaire M, Sun F et al. (1992) Close linkage of glucokinase locus on chromosome $7 \mathrm{p}$ to early-onset noninsulin-dependent diabetes mellitus. Nature 356: 162-164
23. Matschinsky FM (1996) Banting Lecture 1995. A lesson in metabolic regulation inspired by the glucokinase glucose sensor paradigm. Diabetes 45: 223-241

24. Stoffers DA, Ferrer J, Clarke WL, Habener JF (1997) Early-onset type-II diabetes mellitus (MODY4) linked to IPF1. Nat Genet 17: 138-139

25. Harrela M, Koistinen H, Kaprio J et al. (1996) Genetic and environmental components of interindividual variation in circulating levels of IGF-I, IGF-II, IGFBP-1, and IGFBP3. J Clin Invest 98: 2612-2615

26. Kaprio J, Sarna S, Koskenvuo M, Rantasalo I (1978) The Finnish Twin Registry: formation and compilation, questionnaire study, zygosity determination procedures, and research program. Prog Clin Biol Res 24 Pt B:179-184

27. Sarna S, Kaprio J, Sistonen P, Koskenvuo M (1978) Diagnosis of twin zygosity by mailed questionnaire. Hum Hered 28: 241-254

28. Segal KR, Gutin B, Presta E, Wang J, Van Itallie TB (1985) Estimation of human body composition by electrical impedance methods: a comparative study. J Appl Physiol 58: 1565-1571

29. Franssila-Kallunki A (1992) Comparison of near-infrared light spectroscopy, bioelectrical impedance and tritiated water techniques for the measurement of fat-free mass in humans. Scand J Clin Lab Invest 52: 879-885

30. Lehto M, Tuomi T, Mahtani M et al. (1997) Characterization of the MODY3 phenotype: Early-onset diabetes caused by an insulin secretion defect. J Clin Invest 99: 582-591

31. Williams CJ, Christian JC, Norton JA Jr (1992) TWINAN90: a FORTRAN program for conducting ANOVAbased and likelihood-based analyses of twin data. Comput Methods Programs Biomed 38: 167-176

32. Neale MC, Cardon LR (1992) Methodology for Genetic Studies of Twins and Families. NATO ASI Series. Vol 67, Kluwer Academic Publishers, Dordrecht

33. World Health Organization Study Group on Diabetes Mellitus (1985) Technical report series No 727, WHO, Geneva

34. Åkerman BA, Fischbein S (1992) Within-pair similarity in $\mathrm{MZ}$ and DZ twins from birth to eighteen years of age. Acta Genet Med Gemellol (Roma) 41: 155-164

35. McCartney K, Harris MJ, Bernieri F (1990) Growing up and growing apart: a developmental meta-analysis of twin studies. Psychol Bull 107: 226-237

36. Torgersen AM (1987) Longitudinal research on temperament in twins. Acta Genet Med Gemellol (Roma) 36: 145-154

37. Elbein SC, Ward WK, Beard JC, Permutt MA (1988) Molecular-genetic analysis and assessment of insulin action and pancreatic beta-cell function. Diabetes 37: 377-382

38. Haffner SM, Stern MP, Hazuda HP, Mitchell BD, Patterson JK (1988) Increased insulin concentrations in nondiabetic offspring of diabetic parents. N Engl J Med 319: 1297-1301

39. Warram JH, Martin BC, Krolewski AS, Soeldner JS, Kahn CR (1990) Slow glucose removal rate and hyperinsulinemia precede the development of type II diabetes in the offspring of diabetic parents. Ann Intern Med 113: 909-915

40. Groop L, Kankuri M, Schalin-Jäntti C et al. (1993) Association between polymorphism of the glycogen synthase gene and non-insulin-dependent diabetes mellitus. N Engl J Med 328: 10-14

41. Groop L, Forsblom C, Lehtovirta M (1997) Characterization of the prediabetic state. Am J Hypertens 10: 172S-180S

42. Vaag A, Henriksen J, Beck-Nielsen H (1992) Decreased insulin activation of glycogen synthase in skeletal muscles in young nonobese Caucasian first-degree relatives of pa- 
tients with non-insulin-dependent diabetes mellitus. J Clin Invest 89: 782-788

43. Vauhkonen I, Niskanen L, Vanninen E, Kainulainen S, Uusitupa M, Laakso M (1998) Defects in insulin secretion and insulin action in non-insulin-dependent diabetes mellitus are inherited - metabolic studies on offspring of diabetic probands. J Clin Invest 101: 86-96

44. Byrne M, Sturis J, Sobel R, Polonsky K (1996) Elevated plasma glucose $2 \mathrm{~h}$ postchallenge predicts defects in $\beta$-cell function. Am J Physiol 270:E572-E579

45. Vaag A, Henriksen JE, Madsbad S, Holm N, Beck-Nielsen H (1995) Insulin secretion, insulin action, and hepatic glucose production in identical twins discordant for non-insulin-dependent diabetes mellitus. J Clin Invest 95: 690-698

46. Cerasi E, Luft R (1967) Insulin response to glucose infusion in diabetic and non-diabetic monozygotic twin pairs. Genetic control of insulin response? Acta Endocrinol 55: 330-345

47. Rorsman P (1997) The pancreatic beta-cell as a fuel sensor - an electrophysiologists viewpoint. Diabetologia 40: 487-495

48. Hong Y, Pedersen NL, Brismar K, Hall K, de Faire U (1996) Quantitative genetic analyses of insulin-like growth factor I (IGF-I), IGF-binding protein-1, and insulin levels in middle-aged and elderly twins. J Clin Endocrinol Metab 81: 1791-1797

49. Hong Y, Pedersen NL, Brismar K, de Faire U (1997) Genetic and environmental architecture of the features of the insulin-resistance syndrome. Am J Hum Genet 60: 143-152

50. Narkiewicz K, Chrostowska M, Kuchta G et al. (1997) Genetic influences on insulinemia in normotensive twins. Am J Hypertens 10: 467-470

51. Mayer EJ, Newman B, Austin MA et al. (1996) Genetic and environmental influences on insulin levels and the insulin resistance syndrome: an analysis of women twins. Am J Epidemiol 143: 323-332

52. Snieder H, Boomsma DI, van Doornen LJP, Neale MC (1999) Bivariate genetic analysis of fasting insulin and glucose levels. Genet Epidemiol 16: 426-446

53. Laakso M (1993) How good a marker is insulin level for insulin resistance? Am J Epidemiol 137: 959-965

54. Utriainen T, Holmäng A, Björntorp P et al. (1996) Physical fitness, muscle morphology, and insulin-stimulated limb blood flow in normal subjects. Am J Physiol 270: E905-E911

55. Nyholm B, Mengel A, Nielsen S et al. (1996) Insulin resistance in relatives of NIDDM patients: the role of physical fitness and muscle metabolism. Diabetologia 39: 813-822

56. Kaprio J, Koskenvuo M, Sarna S (1981) Cigarette smoking, use of alcohol, and leisure-time physical activity among same-sexed adult male twins. Prog Clin Biol Res 69: 37-46

57. Perusse L, Tremblay A, Leblanc C, Bouchard C (1989) Genetic and environmental influences on level of habitual physical activity and exercise participation. Am J Epidemiol 129: 1012-1022
58. Mayer EJ, Newman B, Quesenberry CP Jr, Selby JV (1993) Usual dietary fat intake and insulin concentrations in healthy women twins. Diabetes Care 16: 1459-1469

59. de Castro JM (1993) Genetic influences on daily intake and meal patterns of humans. Physiol Behav 53: 777-782

60. Mayerdavis EJ, Monaco JH, Hoen HM et al. (1997) Dietary fat and insulin sensitivity in a triethnic population the role of obesity - the Insulin Resistance Atherosclerosis Study (Iras). Am J Clin Nutr 65: 79-87

61. Facchini FS, Hollenbeck CB, Jeppesen J, Chen YD, Reaven GM (1992) Insulin resistance and cigarette smoking. Lancet 339: 1128-1130

62. Poulsen P, Vaag A, Beck-Nielsen H (1999) Does zygosity influence the metabolic profile of twins? A population based cross sectional study. BMJ 319: 151-154

63. Rice T, Perusse L, Bouchard C, Rao DC (1996) Familial clustering of abdominal visceral fat and total fat mass: the Quebec Family Study. Obes Res 4: 253-261

64. Rice T, Despres JP, Daw EW et al. (1997) Familial resemblance for abdominal visceral fat: the HERITAGE family study. Int J Obes Relat Metab Disord 21: 1024-1031

65. Hong YL, Rice T, Gagnon J et al. (1998) Familial clustering of insulin and abdominal visceral fat: the HERITAGE family study. J Clin Endocrinol Metab 83: 4239-4245

66. Groop L, Forsblom C, Lehtovirta M et al. (1996) Metabolic consequences of a family history of NIDDM (the Botnia study): evidence for sex-specific parental effects. Diabetes 45: $1585-1593$

67. Fujisawa T, Ikegami H, Kawaguchi Y, Ogihara T (1998) Meta-analysis of the association of Trp64Arg polymorphism of beta 3 -adrenergic receptor gene with body mass index. J Clin Endocrinol Metab 83: 2441-2444

68. Allison DB, Heo M, Faith MS, Pietrobelli A (1998) MetaAnalysis of the Association of the Trp64arg Polymorphism in the Beta(3) Adrenergic Receptor With Body Mass Index. Int J Obes 22: 559-566

69. Widén E, Lehto M, Kanninen T, Walston J, Shuldiner AR, Groop LC (1995) Association of a polymorphism in the beta 3-adrenergic-receptor gene with features of the insulin resistance syndrome in Finns. N Engl J Med 333: 348-351

70. Mitchell BD, Blangero J, Comuzzie AG et al. (1998) A paired sibling analysis of the beta-3 adrenergic receptor and obesity in Mexican Americans. J Clin Invest 101: 584-587

71. Hoffstedt J, Poirier O, Thorne A et al. (1999) Polymorphism of the human beta3-adrenoreceptor gene forms a well-conserved haplotype that is associated with moderate obesity and altered receptor function. Diabetes 48: 203-205

72. Umekawa T, Yoshida T, Sakane N, Kogure A, Kondo M, Honjyo H (1999) Trp64Arg mutation of beta3-adrenoreceptor gene deteroriates lipolysis induced by beta3-adrenoreceptor agonist in human omental adipocytes. Diabetes 48: $117-120$

73. Klannemark M, Orho M, Langin D et al. (1998) The putative role of the hormone-sensitive lipase gene in the pathogenesis of Type II diabetes mellitus and abdominal obesity. Diabetologia 41: 1516-1522 